\title{
Software
}

\section{Obtención, edición y gestión de imágenes mediante recursos de libre acceso}

\author{
Por Lluís Codina
}

\begin{abstract}
Resumen: El mundo de la imagen es en la actualidad una de las zonas privilegiadas de los sistemas cooperativos y de libre uso. Una buena selección de herramientas en todos o en algunos de los apartados siguientes: búsqueda y selección, edición y gestión, puede proporcionar oportunidades a organismos, por ejemplo del ámbito cultural, que no dispongan de financiación específica para proyectos multimedia. Se presentan en este trabajo los siguientes recursos: YotoPhoto, Paint.NET y XnView.
\end{abstract}

Palabras Clave: Documentación multimedia, Búsqueda multimedia, Imágenes, Edición de imágenes, Gestión de imágenes, YotoPhoto, Paint.NET, XnView.

\section{Title: Obtaining, editing and managing images with free and open ac- cess resources}

Abstract: The world of images is currently one of the privileged areas for cooperative systems and free use. A good selection of tools is available that address all or some of the following tasks: (1) search and selection, (2) editing and (3) management. This offers opportunities for cultural entities that do not have funding for multimedia. Three specific resources are described: YotoPhoto, Paint.NET and XnView.

Keywords: Multimedia documents, Multimedia search, Images, Image edition, Image Management, YotoPhoto, Paint.NET, XnView.

Codina, Lluís. "Obtención, edición y gestión de imágenes mediante recursos de libre acceso". En: El profesional de la información, 2007, septiembre-octubre, v. 16, n. 5, pp. 512-517.

DOI: 10.3145/epi.2007.sep.15

\section{Introducción}

\section{PODEMOS CONTEMPLAR}

EL CICLO DE VIDA de un fondo documental de imágenes como algo compuesto por las fases de producción u obtención, edición y gestión.

En este trabajo presentamos un grupo de recursos de acceso libre que cubren cada una de las etapas mencionadas. En el primer apartado, comentaremos el caso del buscador YotoPhoto, en el segundo, el editor de imágenes Paint.NET y en el tercero el gestor de imágenes XnView. Todas las aplicaciones que se presentan aquí se caracterizan por ser de coste cero.

\section{Obtención de imágenes}

La forma habitual de obtener imágenes para un proyecto editorial o multimedia no puede descansar en el uso de los motores de búsqueda convencionales como Google, por ejemplo. El motivo es doble: por un lado, la calidad de los materiales que se recuperan mediante un buscador suele dejar mucho que desear en cuanto a su uso profesional. Pero aún así, lo más importante con diferencia es la cuestión de los derechos de autor. Los motores de búsqueda pueden localizar información basándose en algún elemento contextual, por ejemplo el nombre del fichero de imagen. Pero como es lógico lo ignoran todo sobre lo que atañe a los derechos de autor: quién es el propietario de los mismos o a quién dirigirse en caso de estar interesados en su uso, si la imagen es susceptible de uso comercial, etc.
Para proyectos profesionales que disponen de financiación, la vía más eficiente consiste en recurrir a bancos de imágenes como $A G E$ Fotostock, Corbis o Getty Images, por mencionar solamente tres de los más conocidos.

No obstante, como solemos argumentar en esta serie de trabajos, en ocasiones algunos proyectos vinculados a actividades culturales ni cuentan con financiación específica ni están destinados a una explotación comercial. En ese caso, de no disponer de fuentes alternativas, probablemente el proyecto simplemente no se llevaría a cabo. Aquí presentaremos tres fuentes de obtención de imágenes que, al mismo tiempo que disponen de licencias bien especificadas 
de cesión de derechos, son de coste cero.

\subsection{YotoPhoto}

Ha sido desarrollado por una pequeña compañía privada del mismo nombre ubicada en Canadá. Consiste en un motor de búsqueda de imágenes de dominio público, es decir, distribuidas típicamente bajo licencias Creative Commons o $G N U$ así como, en general, distribuidas por sus propios autores bajo cualquier tipo de licencia explícita de uso más o menos libre.

\section{http://www.yotophoto.com}

Tal como explican en su propia página de créditos, nació en el año 2005 como un experimento de indización de las imágenes de Wikipedia. Su fundador y presidente, Mark Thomson, un profesional vinculado al mundo de la web y la publicación en línea, explica que inicialmente la idea consistió en mejorar el motor de búsqueda interno de la enciclopedia.

En la actualidad indiza las imágenes de diversos repositorios de imágenes, entre ellos Flickr, MorgueFile y Stcok.Xchng, además de Wikipedia, y proporciona de este modo una interfaz de búsqueda unificada a unas doscientas cincuenta mil imágenes ubicadas en los distintos servidores. YotoPhoto, al igual que otros motores de búsqueda, acepta propuestas de inclusión de sitios web (existe un formulario para ello).

La búsqueda y la descripción de las imágenes, comparadas con la de un banco de imágenes comercial, es bastante pobre. Por ejemplo, no contempla ninguna posibilidad de navegación e incluso la búsqueda avanzada presenta limitaciones, siempre si la comparamos con servicios equivalentes de pago. Pero hemos de entender que es algo lógico dado el carácter cooperativo o voluntario que presenta toda la cadena. Desde el autor que cede el uso de las imágenes pasando por los servido-

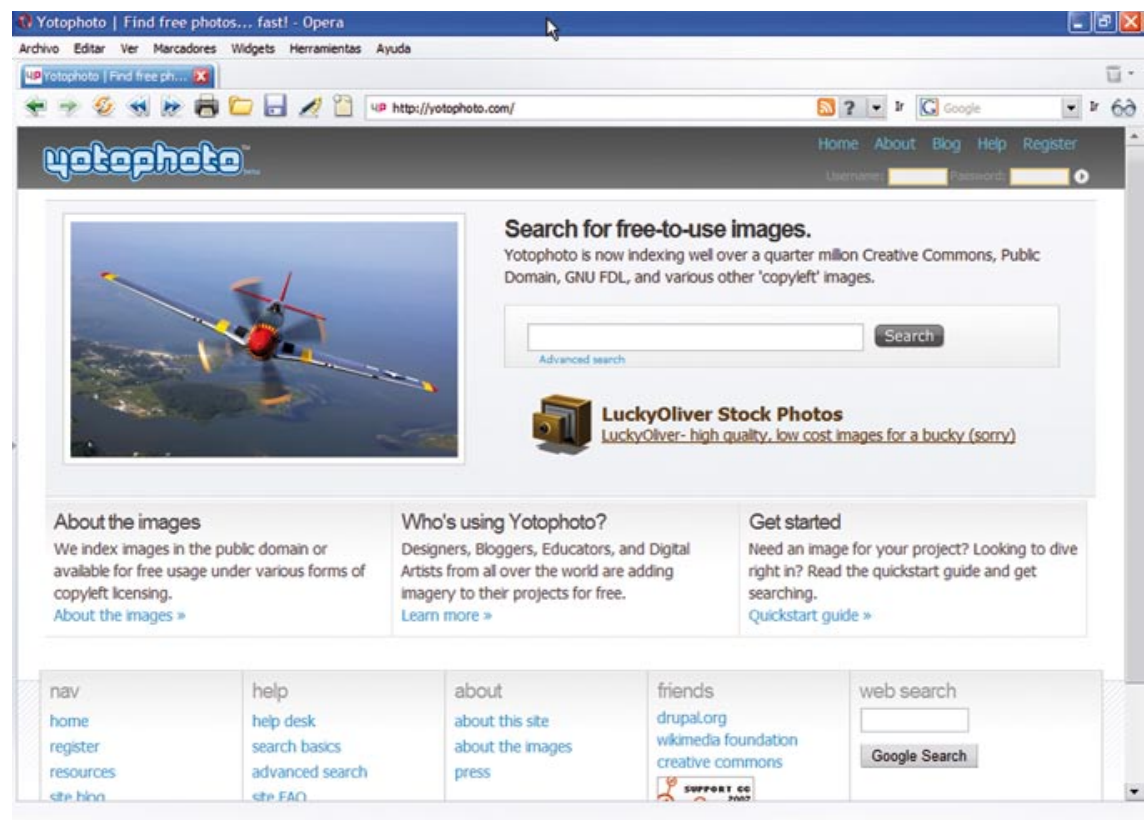

Figura 1. Página principal de YotoPhoto, motor de búsqueda de imágenes bajo licencias de tipo copyleft

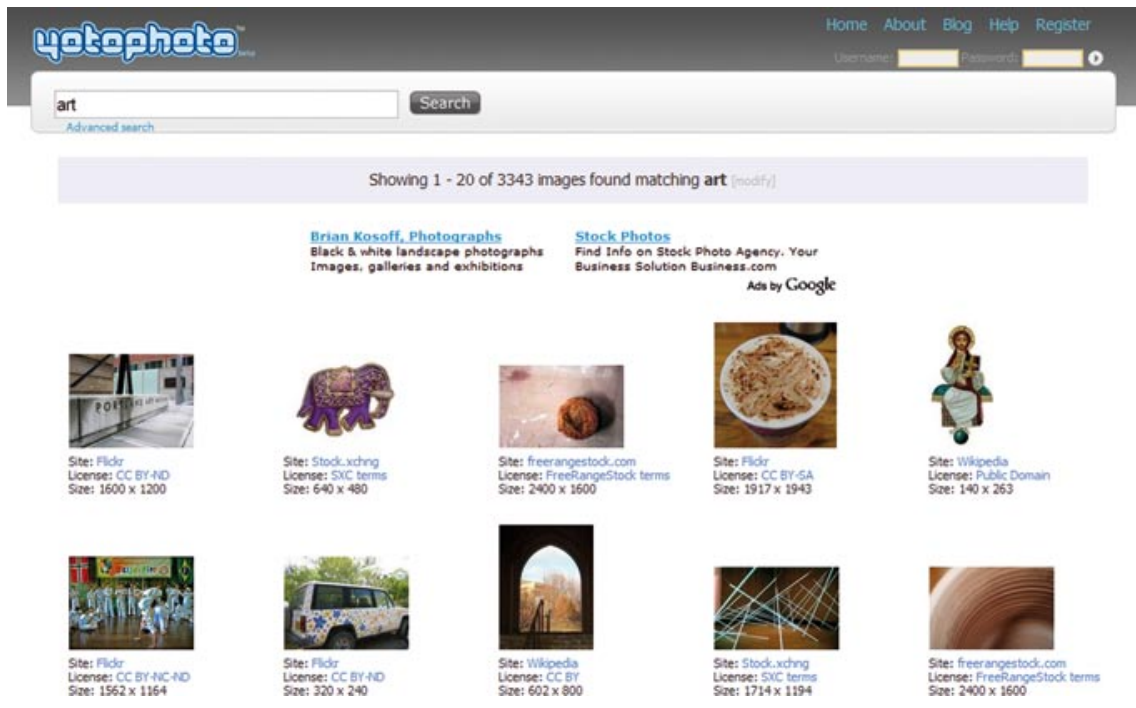

Figura 2. Página de resultados de YotoPhoto. Para cada resultado indica el sitio web de origen y el tipo de licencia además del tamaño de la imagen

res implicados y finalizando en el usuario, no tiene lugar transacción alguna: es decir, nadie paga, nadie cobra (excepto el propio YotoPhoto que muestra una discreta actividad publicitaria). No es extraño pues que el servicio presente limitaciones.

En cambio, la visualización de las imágenes particulares es sumamente correcta, con una disposición muy similar a la que podemos obtener de los sitios comerciales mencionados: una reproducción aceptablemente amplia y un conjunto de informaciones complementarias.

\section{2. Alternativas}

Las más obvias son los propios sitios que indiza y que suelen poseer también motores de búsqueda, siendo los más importantes probablemente los siguientes:

- Flickr.

http://www.flickr.com

- Stock.xchng.

http://www.sxc.hu/

- MorgueFile.

http://www.morguefile.com 


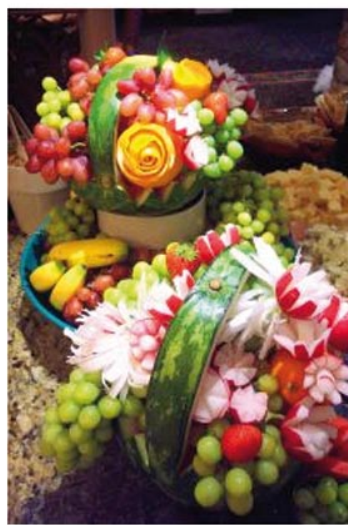

Photo \#432772 Add to favourites View image license

rate image ...-

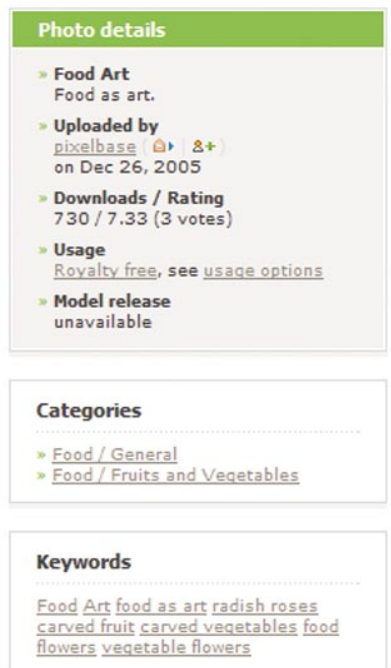

Figura 3. YotoPhoto: visualización de una imagen individual. Obsérvese, entre otras informaciones, el número de veces que ha sido descargada, el tipo de licencia, la categorización, etc.

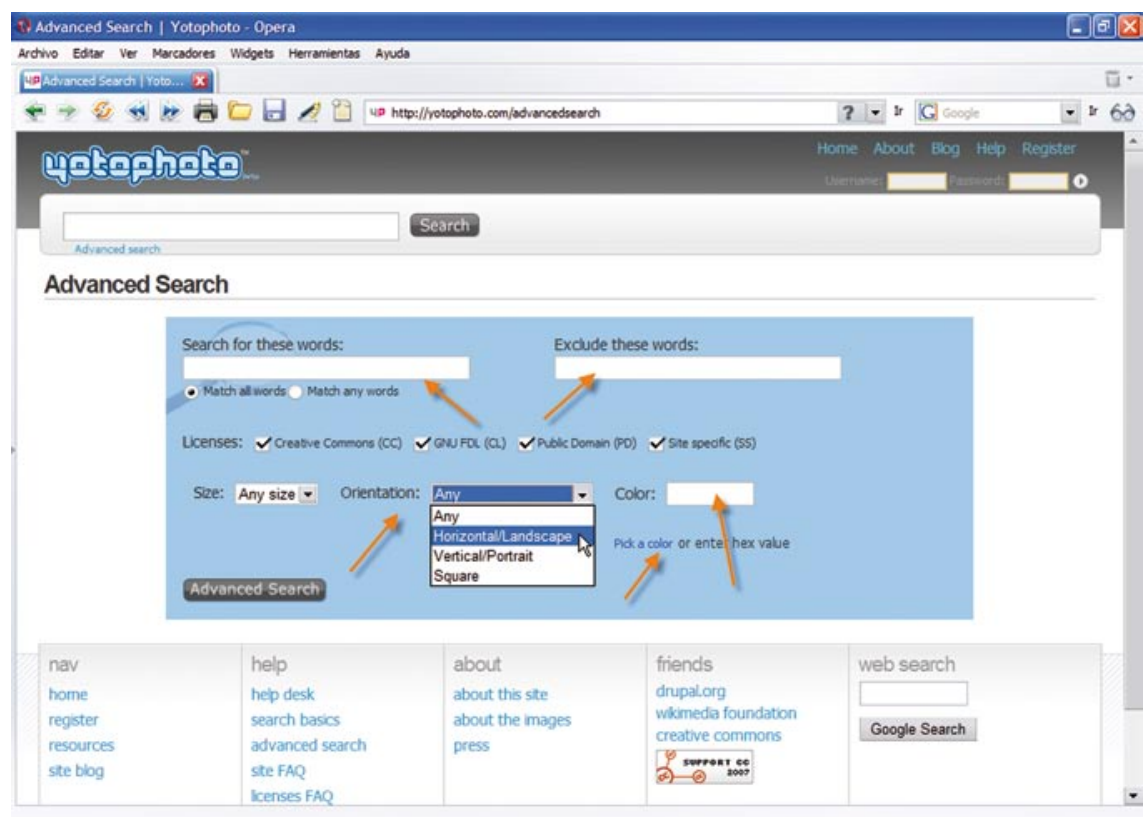

Figura 4. YotoPhoto: formulario de búsqueda avanzada. Permite un uso limitado de operadores booleanos, pero incorpora opciones como seleccionar la orientación de la imagen o el color dominante, opciones muy importantes para los diseñadores.

\section{- ImageAfter}

http://www.imageafter.com

Seguramente espoleados por el ejemplo de YotoPhoto, desde hace algún tiempo motores de búsqueda como Google o Yahoo permiten, a través de las opciones de la búsqueda avanzada, restringir los resultados a imágenes con licencia creative commons, y otro tanto puede hacerse desde la página de búsqueda de la propia web de Creative Commons http://es.creativecommons.org/ espacio/buscar.php

\section{Edición}

En el apartado de edición de imágenes en general y de fotografías en particular, el mundo del software gratuito (freeware) y/o de código abierto (open source) es especialmente generoso. Contamos con media docena al menos de programas gratuitos, siendo GIMP probablemente no sólo uno de los más conocidos sino también de los más completos. No obstante, debido a la gran cantidad de opciones que presenta y a una forma de distribución poco amigable, aparece para algunos usuarios como un programa intimidatorio. Existen pocas dudas, sin embargo, entre los expertos sobre su enorme eficacia.

htp://www.gimp.org/

\section{"En el apartado de edición de imágenes en general y de fotografías en particular el mundo del software gratuito y/o de código abierto es especialmente generoso"}

En esta ocasión hemos elegido presentar Paint.NET, en parte porque es hasta cierto punto un recién llegado, al menos comparado con la veteranía del anterior, y además por su facilidad de uso.

\subsection{Paint.NET}

Es un programa general de edición de imágenes y fotografías que comenzó como un proyecto académico de prácticas de la Washington State University. Dado el alto nivel de calidad conseguido, pronto pasó a tener vida independiente y desde algún tiempo se distribuye de forma gratuita, bajo una licencia creative commons. Sigue siendo mantenido por el profesor que guió el proyecto original y por parte de los alumnos que le dieron vida en su momento. Mantiene un excelente ritmo de desarrollo con frecuentes mejoras y nuevas versiones, así como con una activa comunidad de usuarios.

\section{http://www.getpaint.net}

Probablemente sus mejores cualidades sean su facilidad de uso y su elegante interfaz, unidos a una baja demanda de requerimientos de hardware, pese a lo cual su lista de fun- 
ciones es realmente impresionante y queda a la altura de la de muchos programas comerciales de su categoría, excepción hecha de pesos pesados como PhotoShop o GIMP.

\subsection{Alternativas}

La mejor opción de tipo gratuito u open source es el ya mencionado GIMP. Como hemos señalado antes, GIMP es un programa más completo, pero también más complejo y requiere mayor cantidad de recursos de hardware. En todo caso, su gran ventaja es que se trata de un programa multiplataforma: funciona en Linux, Mac y Windows, mientras que Paint.NET sólo funciona en Windows.

Otros dos programas de gran calidad y que cuentan con una gran aceptación son FotoFiltre y Pixia, éste último más orientado al dibujo aunque también incluye opciones para la edición de imágenes.

http://www.photofiltre-studio. com/

http://park18.wakwak.com/ $\sim$ pixial

\section{Gestión de imágenes}

Por alguna razón, la gestión de imágenes y fotografías es otro de los terrenos privilegiados del software libre. Ya lo era antes de la eclosión de la fotografía digital, pero ésta ha incrementado aún más la oferta de programas que ofrecen excelentes prestaciones a coste cero. El punto culminante lo marcó probablemente la adquisición de Picasa por parte de Google, momento en el que pasó a ser gratuito. En paralelo, otras grandes empresas de software, como Adobe y Corel han ofrecido sendas versiones gratuitas de sus programas de gestión de imágenes (en este caso, con prestaciones recortadas).

\section{http://picasa.google.com/}

\subsection{XnView}

Presentamos XnView, todo un clásico del software libre que se

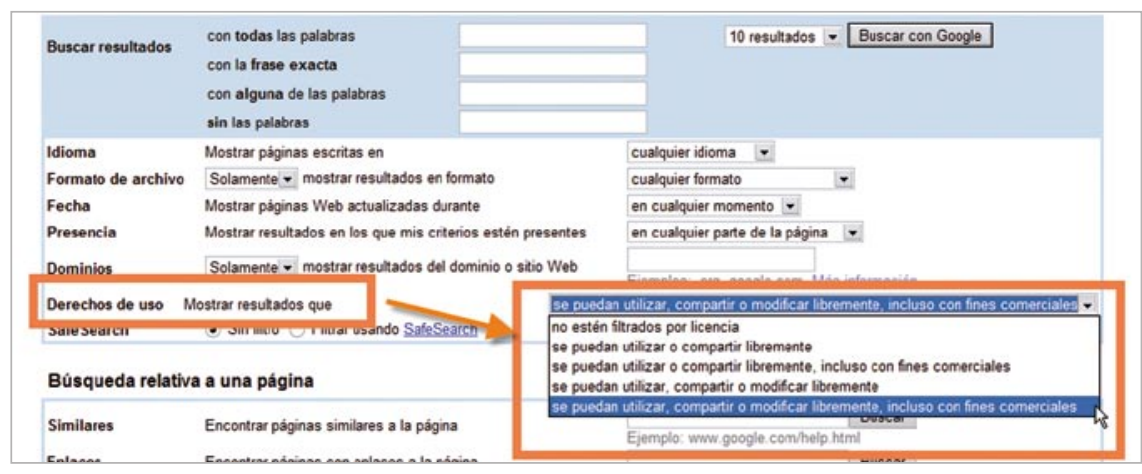

Figura 5. Un tanto camuflado en las opciones avanzadas, Google permite limitar sus búsquedas de documentos (incluyendo imágenes) por el tipo de licencia

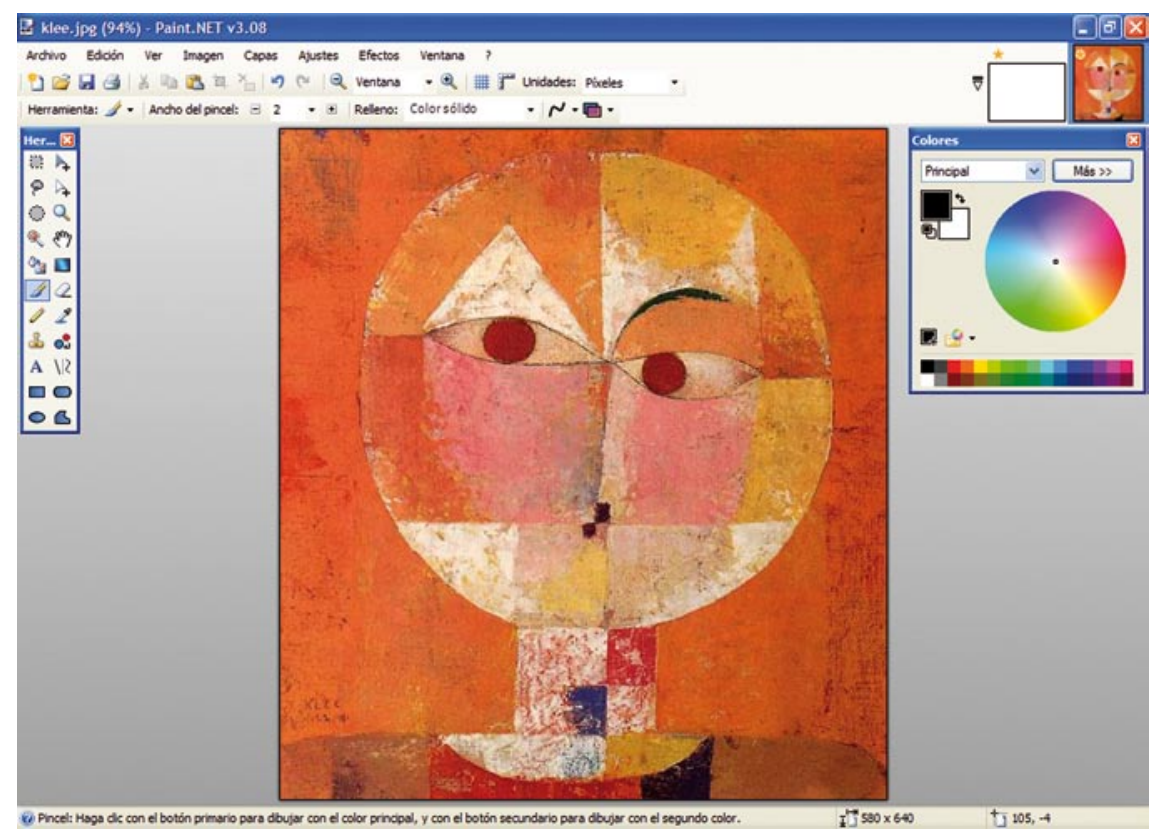

Figura 6. Paint.NET presenta una interfaz simple y clara y con las opciones más importantes a mano

mantiene en excelente forma, con frecuentes actualizaciones y una lista de prestaciones que crece sin parar y sin añadir la más mínima complejidad apreciable al uso del programa.

\section{http://www.xnview.com}

Las funciones de un gestor de imágenes consisten, al menos, en las siguientes:

- Organizar y facilitar el acceso a colecciones de imágenes mediante un sistema de categorización, indización y búsqueda.

- Proporcionar sistemas de visualización: vistas en grupo, individuales, zoom, creación de presenta- ciones, vista de metadatos, etc.

- Ofrecer opciones básicas de edición: color, dimensión, transformaciones, rotaciones, filtros, ajustes, etc.

- Facilitar operaciones de mantenimiento: cambio y exportación de formatos, creación de miniaturas (para páginas web), creación de hojas de contacto, realización de cambios globales, etc.

XnView proporciona todos los grupos de funciones anteriores $y$ añade algunas más; por ejemplo es un capturador de pantallas, así como puede importar directamente imágenes de una cámara fotográfica. 


\begin{tabular}{|c|c|c|c|c|c|}
\hline \multicolumn{2}{|c|}{ Efectos } & Ventana ? & & & \\
\hline & \multicolumn{2}{|c|}{ Desenfoques } & • & 10 & Desenfocado de movimiento... \\
\hline & \multicolumn{2}{|c|}{ Distorsión } & 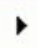 & $\because$ & Desenfocado de zoom... \\
\hline$\because \therefore$ & \multicolumn{2}{|c|}{ Agregar ruido... } & & Ms & Desenfocado gausiano... \\
\hline Q & \multicolumn{2}{|c|}{ Boceto a lápiz... } & & (Q) & Desenfocado radial... \\
\hline 0 & \multicolumn{2}{|c|}{ Brillo... } & & bु & Desenfocar... \\
\hline प्रे & \multicolumn{2}{|c|}{ Contorno... } & & 言 & Mediana... \\
\hline 承: & \multicolumn{3}{|c|}{ Cristal congelado... } & & \\
\hline 芦 & \multicolumn{3}{|c|}{ Detección de perímetro... } & & \\
\hline$\infty$ & \multicolumn{3}{|c|}{ Eliminar ojos rojos... } & & \\
\hline 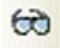 & \multicolumn{3}{|c|}{ Enfoque... } & & \\
\hline$\theta$ & \multicolumn{3}{|c|}{ Nubes... } & & \\
\hline 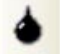 & \multicolumn{3}{|c|}{ Pintar con aceite... } & & \\
\hline 㬂 & \multicolumn{3}{|c|}{ Pixelado... } & & \\
\hline Ac & \multicolumn{3}{|c|}{ Realce... } & & \\
\hline 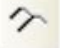 & \multicolumn{3}{|c|}{ Relieve... } & & \\
\hline
\end{tabular}

Figura 7. Menú de efectos de Pain.NET con una sola de sus 15 subopciones desplegada

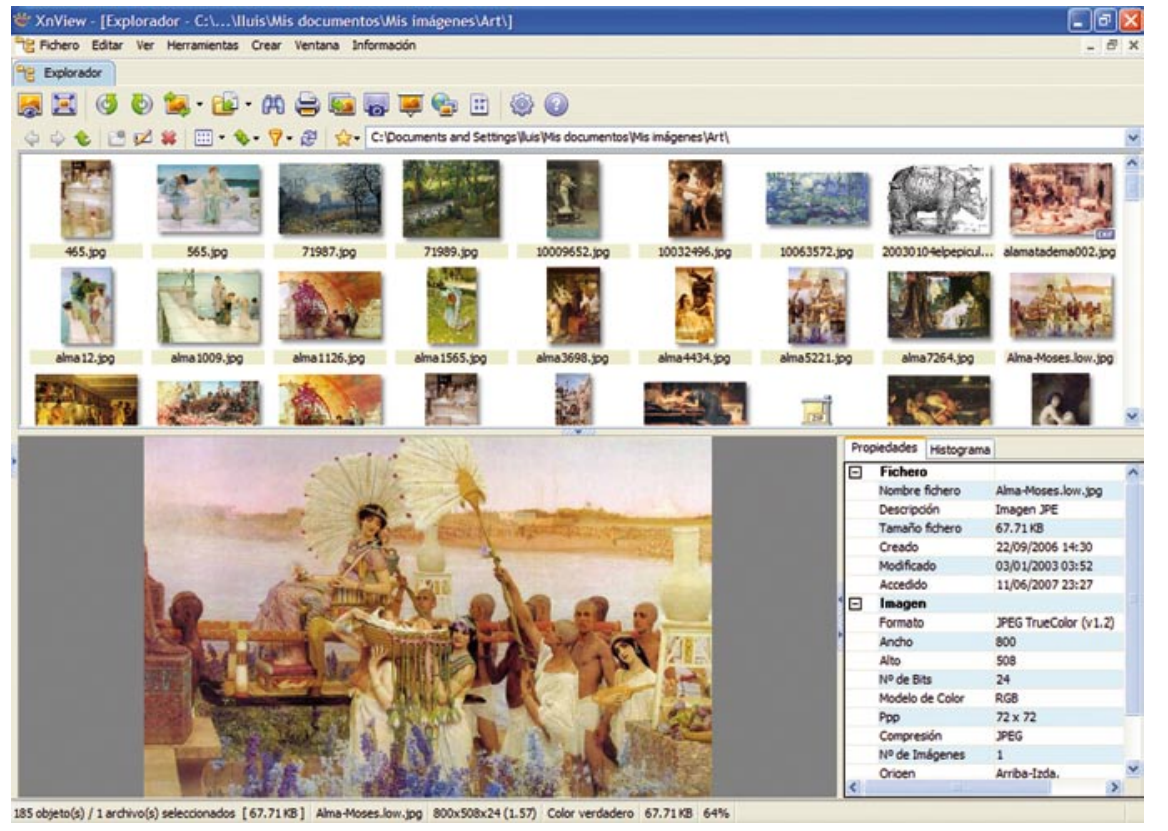

Figura 8. XnView como explorador de imágenes. Su interfaz se puede dividir en varias ventanas. En esta ocasión vemos la lista de imágenes mediante miniaturas, una visión ampliada de la imagen seleccionada y la ventana de metadatos al lado.

\subsection{Alternativas}

Para quienes necesiten trabajar intensamente con fotografías digitales, y los documentos más importantes sean siempre los últimos (no los de hace un año, y menos los de hace dos) Picasa puede ser la mejor opción. No posee tantas funciones como XnView, pero a cambio es de gital y las opciones típicas de distribución asociadas a ella: publicar en la web, enviar por correo electrónico, etc. No posee las excelentes funciones de edición de XnView, ni proporciona tantas herramientas de categorización, búsqueda y trabajo con metadatos, pero en muchos entornos apreciarán su enorme facilidad de uso si no necesitan esas opciones.

Otro programa que goza de gran aceptación es IrfanView. De los tres es el que ofrece menos funciones, pero ocupa un espacio insignificante en el disco duro y es de una ejecución rapidísima. Si solamente necesitamos un sistema muy rápido de visualización y operaciones básicas de edición y mantenimiento, puede ser la mejor opción.

\section{http://www.irfanview.com}

\section{Conclusiones}

Tal como hemos señalado, el mundo de la imagen es una de las zonas privilegiadas de los sistemas cooperativos tan propios de la web 2.0 y de los sistemas basados en licencias open source o creative commons. Una buena selección de estas herramientas en todos o en algunos de los apartados relacionados puede proporcionar grandes oportunidades a muchos organismos, por ejemplo del mundo de la cultura, tan típicamente escaso de recursos.

No siempre pueden sustituir a las opciones correspondientes de alta tecnología (sistemas corporativos cliente-servidor) o de muy alta calidad (bancos de imágenes para campañas de publicidad); pero antes que renunciar a algún proyecto creativo que involucre el uso o la gestión adecuada de imágenes por
"Antes que renunciar a algún proyecto creativo por no disponer de presupuestos específicos, cabría considerar recursos como los presentados aquí" un uso aún más fácil y está totalmente orientado a la fotografía di- 


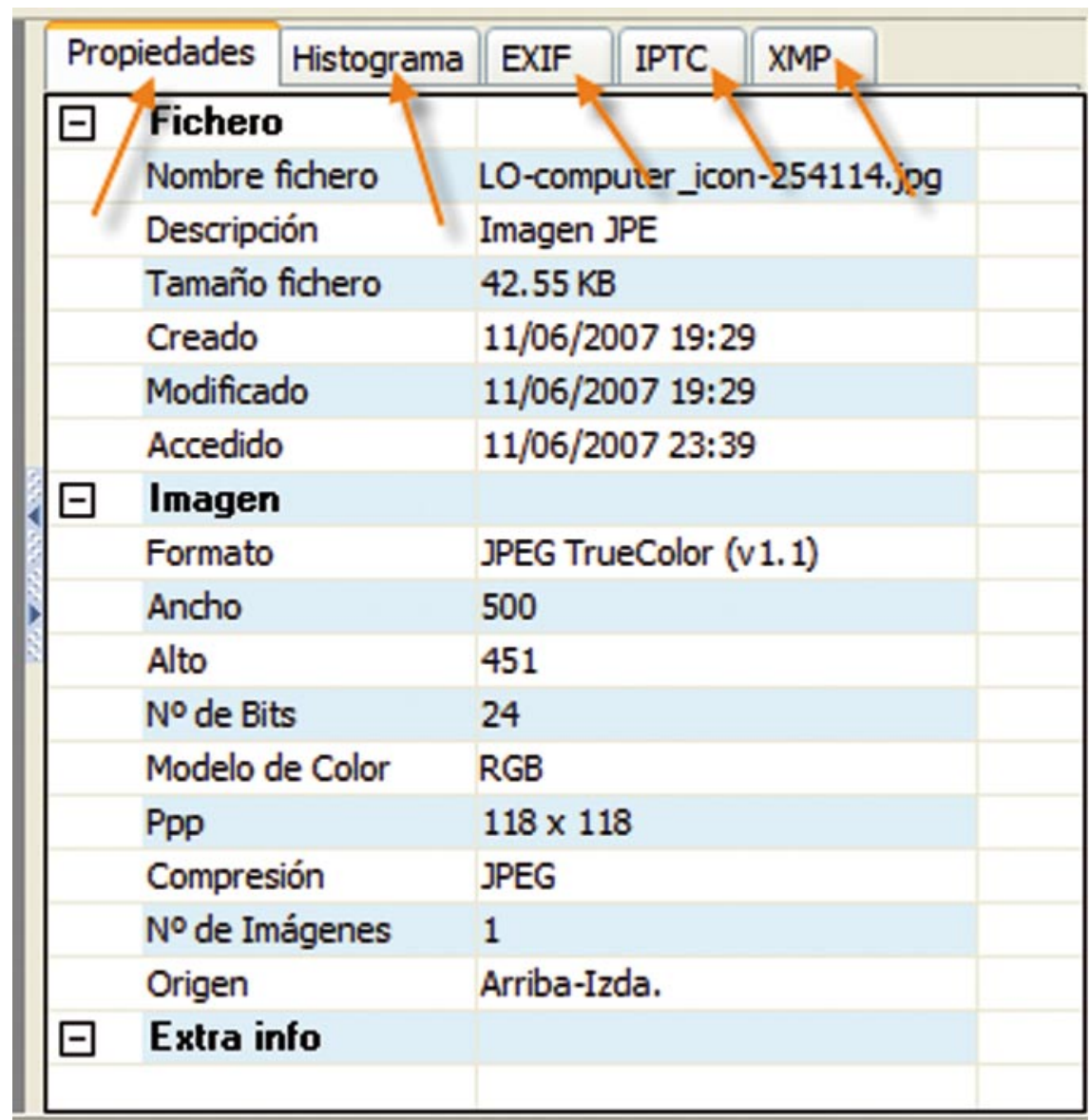

Figura 9. Visión detallada de la ventana de metadatos de XnView que se abre de forma automática con cada imagen (aunque se puede desactivar la opción). Obsérvese que presenta metadatos EXIF, IPTC e XMP, además de las propiedades de la imagen.

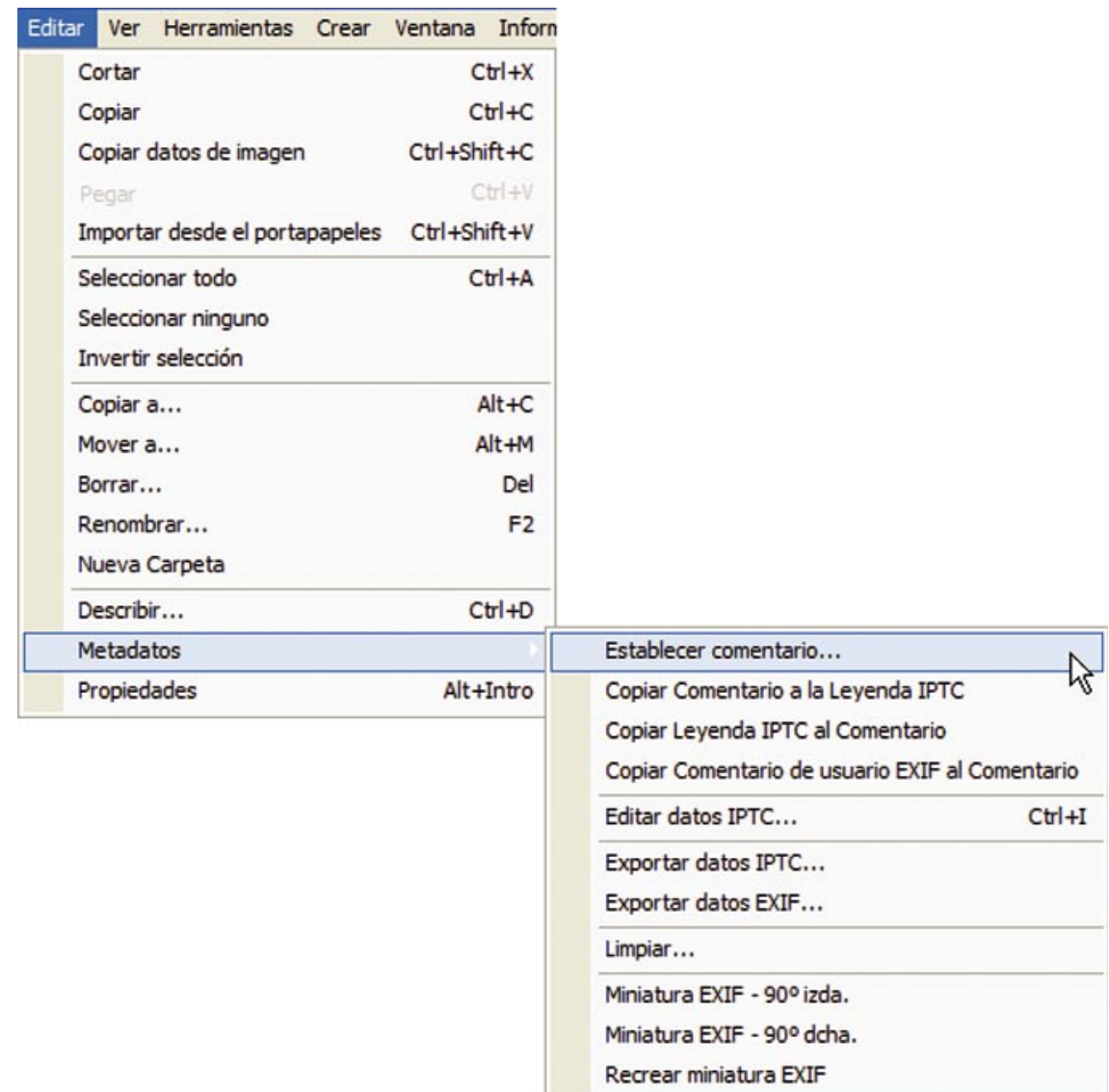

Figura 10. Vemos las operaciones que $\mathrm{XnView} \mathrm{permite} \mathrm{realizar} \mathrm{como} \mathrm{editor} \mathrm{de} \mathrm{metadatos:} \mathrm{añadir}$ anotaciones (crear metadatos), copiar metadatos y exportarlos a ficheros de texto externos no disponer de presupuestos específicos al tratarse tal vez de trabajos no destinados al mercado, cabría considerar recursos descritos.

Es indudable que de ellos pueden beneficiarse universidades, ONG, investigadores de la comunicación, sitios web y portales de organismos sin ánimo de lucro, etc.: la lista en realidad es enorme. ¿Qué organismo no necesita imágenes para su sitio web? ¿quién o qué corporación, ONG, etc., no está creando imágenes actualmente mediante cámara digital? ¿quién no dispone ya de un número creciente de imágenes que están reclamando desde hace tiempo una buena gestión? Tal vez los programas expuestos sean al menos un buen punto de partida.

\section{Fuentes}

Alexa Stock Footage.

http://www.alexa.com/browse/general/ ? \& C a t e gory I D $=199005 \& \mathrm{mode}=$ general\&Start=1\&SortBy=Popularity

Alexa Stock Photography.

http://www.alexa.com/browse?\&CategoryID=2 53870

Codina, L.; Palma, M.-del-V.; Cid, P. (coord.). "Gestión de documentación multimedia" (número monográfico). En: El profesional de la información, 2003, noviembre-diciembre, v. 12, n. 6.

Codina, L.; Palma, M.-del-V.; Cid, P. "Búsqueda y acceso a información multimedia en la web" (presentación en ppt). En: IV Jornadas de documentación audiovisual, 2006.

http://www.lluiscodina.com

Coorough, C.; Shunan, J. Multimedia para la web. Madrid: Anaya, 2005.

Galer, M.; Horvat, L. La imagen digital. Madrid: Anaya, 2005

Technical Advisory Service for Images (TASI). http://www.tasi.ac.uk

\section{Lluís Codina, Universidad Pompeu} Fabra.

lluis.codina@upf.edu

http://www.lluiscodina.com 